\title{
The Global Burden of Chronic Kidney Disease: How Valid Are the Estimates?
}

\author{
Richard J. Glassock ${ }^{a}$ Christopher Winearls ${ }^{b}$ \\ aThe David Geffen School of Medicine at UCLA, Los Angeles, Calif., USA; ${ }^{b}$ Oxford Kidney Unit, Oxford, UK
}

\section{Key Words}

Chronic renal disease - End-stage kidney disease •

Epidemiology $\cdot$ Glomerular filtration rate

\begin{abstract}
Background/Aims: The values for the global prevalence of chronic kidney disease (CKD) are poorly understood. Current classification schemas may overstate the prevalance of CKD. This minireview analyzes the pitfalls in the use of current classification approaches for identifying CKD on a global basis. Methods: Literature review and comment. Results: Published estimates for the global burden of CKD are likely to be incorrect and inflated. Overestimations of prevalence have occurred due to flaws in the classification systems employed and in ascertainment methods. Conclusions: A revision of the current system of diagnosing and classifying CKD is needed in order to determine with greater precision true global burden of CKD. A new system is proposed.
\end{abstract}

Copyright $\odot 2008$ S. Karger AG, Basel

\section{Introduction}

Chronic kidney disease (CKD) has a worldwide distribution. Great concern has been repeatedly expressed that $\mathrm{CKD}$ is threatening to reach epidemic proportions thus creating the potential to overwhelm the limited resources of less 'robust' economies [1]. This review is intended to dispassionately examine the global prevalence of CKD in order to better understand its roots as well as to outline new approaches for accurately quantifying the true global burden of CKD.

The story really begins in 2002 when a novel definition, classification and staging system of CKD was promulgated by the National Kidney Foundation (NKF) and the Kidney Disease Outcome Quality Initiative (KDOQI) [2]. Although this construct had not been tested in the field, it was soon adopted as a reference tool for a large number of epidemiological studies throughout the world. Long before KDOQI-CKD, many countries had already established registries to assemble epidemiologic data on the incidence (or more correctly, acceptance rates) and prevalence of treated end-stage renal disease (ESRD). The United States Renal Data System (USRDS) is a preeminent example of this effort [3]. Secular variation in the size of this easily defined ESRD cohort are a direct consequence of a composite of: (i) the actual incidence and prevalence of underlying CKD and its progression to ESRD; (ii) survival from competing causes of mortality prior to the need for renal replacement therapy (RRT); (iii) the acceptance into a RRT program (dialysis and/or transplantation) according to local standards of practice and availability of care; (iv) the overall improvement in patient survival after initiation of RRT. A clear need emerged for the assessment of the overall burden of CKD, prior to RRT, in the community at large. Such an assessment would give insights into the changing pool from which patients destined to develop ESRD must arise. Defining treated ESRD is simple, accurate and straightforward; defining CKD prior to RRT is not. The approach taken by KDOQI was to use multiple and absolute thresh-

\section{KARGER}

Fax +4161306 1234 E-Mail karger@karger.ch www.karger.com

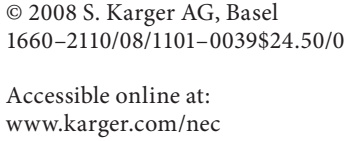


old criteria for defining the stages of CKD [2] (table 1); including an estimate of glomerular filtration rate (eGFR); evidence of 'renal damage' (such as abnormal protein excretion or urinary sediment); structural abnormalities (detected by imaging or renal histology), and including a time dimension (persistence for $\geq 3$ months) to assure true 'chronicity'. The KDOQI construct became the preferred method for epidemiological studies of the CKD burden throughout the world. It was adopted, with only minor modifications by the Kidney Disease Improving Global Outcomes (KDIGO) organization, in 2007 [4].

However, since its introduction, concerns have steadily emerged over the validity of the KDOQI-CKD classification system in identifying 'true' CKD (a disease being an abnormal state which directly or indirectly confers some measurable disadvantage upon an individual compared to a normal one without a disease). These concerns have been cogently expressed, but have not yet yielded any appreciable response in terms of altering the classification schema [5-7]. Questions have also arisen as to how 'transportable' the KDOQI-CKD system is to countries other than the USA, its country of origin.

\section{How Accurate Is the KDOQI Classification in Identifying CKD?}

The KDOQI-CKD classification system comprises five stages (table 1) [2]. CKD stages 1 and 2 require some evidence of 'kidney damage' such as albuminuria (postulated as any magnitude above a 'normal threshold'). CKD stages 1 and 2 are separated from each other based on differences in eGFR, as quantified by an estimating formula, such as the Modification of Diet in Renal Disease (MDRD) four variable equation using a serum creatinine level and knowledge of the age, gender and ancestry (Black or nonBlack) of the individual [8]. The age, gender and ancestry variables serve as surrogates for endogenous creatinine production and excretion. In order to accurately apply the MDRD equation, the serum creatinine value should be calibrated to the standard used to derive the equation or to some other 'gold standard' [9]. The MDRD equation derives eGFR values standardized to 'normal' body surface area [10]. Importantly, the MDRD formula was originally derived from a group of subjects all of whom had well-established kidney disease [8] and was intended to quantify and stratify disease severity and to evaluate its progression not to diagnose kidney disease in subjects without known disease. It soon became apparent that the MDRD equation was inaccurate in estimating 'true' GFR
Table 1. KDOQI definition and staging of CKD, 2002 [1]

\begin{tabular}{lll}
\hline Stage & Description & $\begin{array}{l}\mathrm{eGFR}^{\mathrm{a}} \\
\mathrm{ml} / \mathrm{min} / 1.73 \mathrm{~m}^{2}\end{array}$ \\
\hline 1 & kidney damage $^{\mathrm{b}}$ & $\geq 90$ \\
2 & kidney damage $^{\mathrm{b}}$ & $60-89$ \\
3 & - & $30-59$ \\
4 & - & $15-29$ \\
5 & - & $<15$ or on dialysis \\
\hline
\end{tabular}

a eGFR = estimated glomerular filtration rate. The Modification of Diet in Renal Disease [MDRD] four-variable formula is recommended for estimating GFR [for details, see 2].

${ }^{\mathrm{b}}$ Kidney damage $=$ proteinuria (micro- or macroalbuminuria), hematuria, abnormal composition of blood or urine, abnormal imaging, or abnormal renal biopsy. The qualifying kidney damage and/or eGFR values must persist for $\geq 3$ months.

when the eGFR values were $>60 \mathrm{ml} / \mathrm{min} / 1.73 \mathrm{~m}^{2}$ [11]. Thus, the separation into stage 1 and 2 CKD based on eGFR values of between 60 and $89 \mathrm{ml} / \mathrm{min} / 1.73 \mathrm{~m}^{2}$ (stage 2) and $\geq 90 \mathrm{ml} / \mathrm{min} / 1.73 \mathrm{~m}^{2}$ (stage 1) becomes spurious if one uses the MDRD equation for such stratification. In addition, an eGFR of $<90$ but $>60 \mathrm{ml} / \mathrm{min} / 1.73 \mathrm{~m}^{2}$ is described as mildly reduced, implying that these values are abnormal despite the fact that only a minority of the population at large actually have an eGFR of $>90 \mathrm{ml} / \mathrm{min} / 1.73$ $\mathrm{m}^{2}$. The inclusion of microalbuminuria as meeting the definition of 'kidney damage' in stage 1 or 2 CKD is even more problematical. It is likely that a patient with an established diagnosis of diabetes mellitus (type 1 or type 2) will have an early form of 'incipient' diabetes-related kidney damage if their urinary albumin excretion is raised irrespective of the GFR [12]. But can we say, with a similar level of confidence, that a non-diabetic individual with a similar raised urinary albumin excretion and 'normal' eGFR also has 'kidney damage'? Such albuminuria is commonly found in obese persons, in the presence of systemic chronic inflammation or cancer, and may also be found in apparently healthy elderly individuals [13]. Such states might represent a generalized form of vascular endothelial dysfunction somehow resulting in an abnormal rate of albumin excretion in the urine but is it necessary to label them as suffering from 'kidney damage' or a disease? A risk factor is not a disease. Uncertainty persists as to the mechanisms underlying such abnormal urinary albumin excretion: specifically, is it due to abnormal transglomerular passage of albumin or inefficient reabsorption or reclamation of normally filtered 

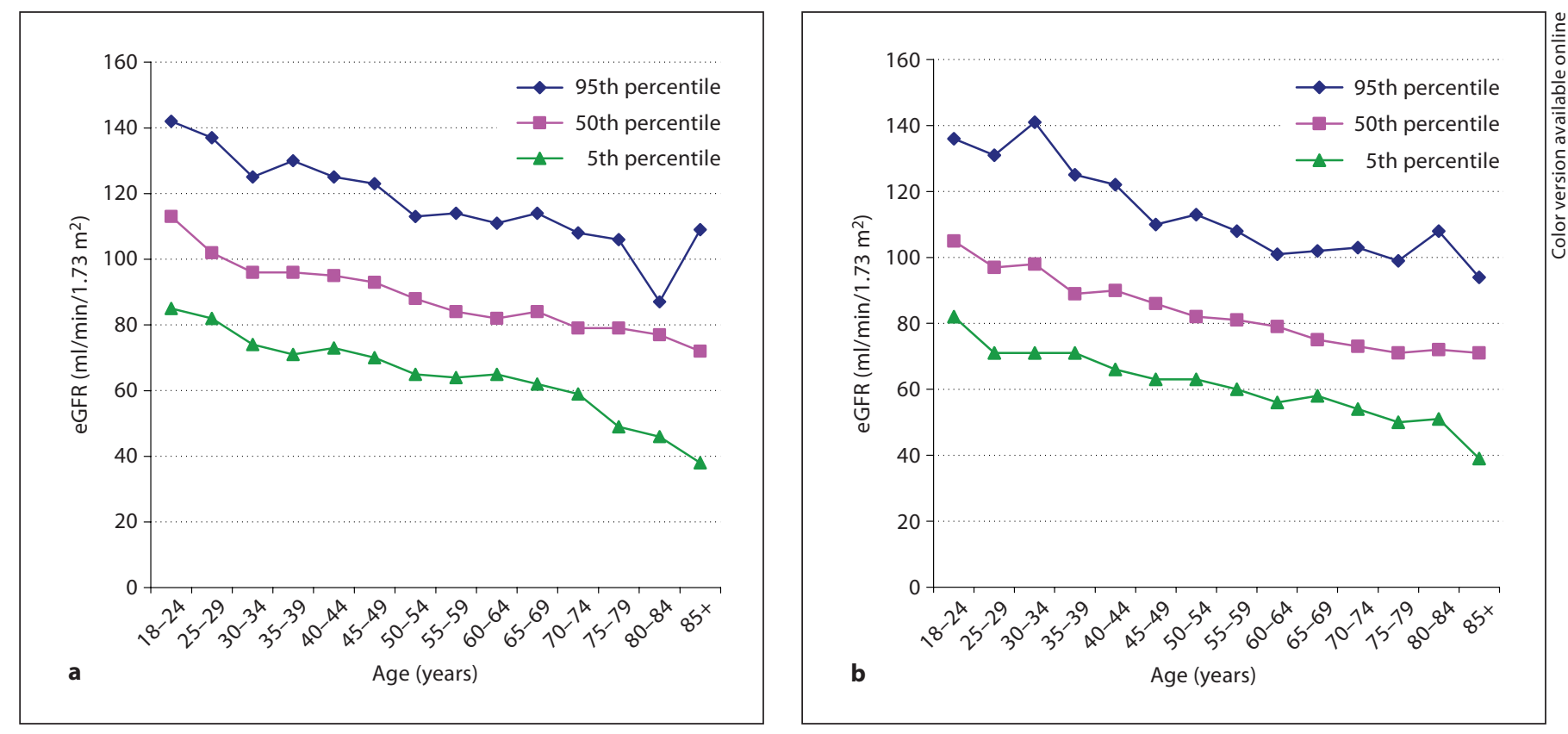

Fig. 1. Reference values for the relationships of eGFR to age by gender; 95,50 and 5 th percentile values. a Nondiseased Caucasian males aged 18 to 85+. b Non-diseased Caucasian females aged 18 to 85+ years. (Data derived from the Nijmegen Biomedical Study using the re-expressed MDRD equation [9]; see Wetzels et al. [21].)

albumin, or both $[14,15]$ ? Many studies have convincingly shown that a rise in albumin excretion rate, above normal but not to levels easily detected by conventional semiquantitative methods ('dipstick positive' proteinuria) is associated with an increased risk of cardiovascular events, including perhaps the development of hypertension [16, 17]. But not all studies are in agreement [18] and it is unclear whether such 'microalbuminuria' is a marker of 'kidney' disease or 'generalized vascular' disease [19]. What is clear is that designating low levels of albumin excretion alone as diagnostic of CKD will greatly inflate the numbers of subjects labeled as having CKD stage 1 or 2 .

Unlike CKD stage 1 and 2, the KDOQI definition of CKD stages 3-5 does not require any corroborating evidence of 'kidney damage'. It is presumed that any eGFR $<60 \mathrm{ml} / \mathrm{min} / 1.73 \mathrm{~m}^{2}$ is 'prima facie' evidence for the presence of kidney disease [2]. Such an arbitrary definition of CKD, using an absolute threshold of eGFR, places many subjects in this category even though they have no other corroborating features of kidney disease. This is particularly true for those categorized as stage 3 CKD (30-59 $\mathrm{ml} / \mathrm{min} / 1.73 \mathrm{~m}^{2}$ ). Thus, an eGFR value of $<60 \mathrm{ml} / \mathrm{min} /$ $1.73 \mathrm{~m}^{2}$ becomes a de facto threshold for the diagnosis of CKD although this estimate has no such precision [5-7].
The values for eGFR decline normally with age and tend to be lower in females than in males [20,21] (fig. 1a, b). The threshold of $<60 \mathrm{ml} / \mathrm{min} / 1.73 \mathrm{~m}^{2}$ for defining stages 3-5 CKD 'captures' a large number of older subjects ( $>65$ years of age) who are otherwise healthy and free of any evidence of 'kidney disease', such as hypertension, diabetes or overt albuminuria, and labels them as having an intermediate stage (3 of 5) of a potentially lethal or life-altering chronic disease. Any subject with an eGFR of $<30 \mathrm{ml} / \mathrm{min} / 1.73 \mathrm{~m}^{2}$ (CKD stages 4 and 5) must surely have significant kidney disease with very rare exceptions (such as severe congestive heart failure with a functional decline in eGFR), irrespective of age, concomitant imaging or urinary findings.

The MDRD method of estimating eGFR was developed from measurements in subjects with well-defined kidney disease and among a heterogeneous population of adults in the USA. It is appropriate to question whether this equation can be applied in an unmodified form to other circumstances, including those with marked differences in lean body mass, habitual protein intake, or geographic ancestry compared to the population from which the equation was derived. Several studies have already shown that the MDRD equation needs modification to meet the circumstances which prevail in a variety 
of populations $[5,22,23]$. The obligate standardization of calculated eGFR to a 'normal' BSA of $1.73 \mathrm{~m}^{2}$ in the MDRD approach also gives rise to some informative anomalies with clinical significance [24]. To illustrate this point, two individuals of identical age, sex, ancestry, serum creatinine concentration and body mass index $\left(\mathrm{kg} / \mathrm{m}^{2}\right)$ but with greatly different calculated body surface area will have the same calculated MDRD eGFR but will have greatly different absolute (uncorrected GFR). The absolute (uncorrected) eGFR is higher in the larger as compared to the smaller subject. Which of the two values for the larger individual is the correct one for determining the presence or absence of CKD?

The legitimacy of the use of eGFR as a method for diagnosing CKD has not been uniformly accepted. For example, recent studies have suggested that the MDRD calculated eGFR was no better than serum creatinine concentration alone in 'diagnosing' CKD, using the current KDOQI criteria $[25,26]$. The necessity for repeated measurement to confirm the 'chronicity' of the decline in eGFR or the persistence of the manifestations of kidney damage imposes a severe limitation upon cross-sectional epidemiological studies. The lack of confirming studies may give rise to many 'false positives', inflating estimates of the prevalence of CKD.

In summary, the KDOQI formulation for diagnosing and stratifying CKD is seriously flawed and its use in the definition of the prevalence of CKD in epidemiologic studies is very likely to yield a marked overestimate of the prevalence of true and relevant CKD in the community at large. These overestimates will most likely be evident in the elderly, especially females, and among otherwise healthy adults with underlying acute or chronic inflammation or with generalized vascular disease. In this latter group, the concept of the presence of a kidney disease is blurred, since many will have some morphological evidence of kidney injury, but only as a part of a more generalized vascular pathology. A further question should be raised regarding the appropriateness of including small increases in urinary albumin excretion to define CKD in the absence of diabetes, hypertension or obesity.

\section{Can the KDOQI Criteria Be Used to Determine the Global Prevalence of CKD?}

The use of the MDRD eGFR formula in populations having characteristics different from those originally used to derive the formula can lead to errors in classification. It seems obvious that the application of the KDOQI criteria will require a population-specific derivation of the estimating equation. This has already been found to be true for both Chinese subjects living in Beijing, and for Japanese subjects $[5,22,23]$. Replacement of serum creatinine with cystatin C-based estimations of GFR, or the use of both values simultaneously may avoid some of these problems but this is not yet proven [27]. Standardization of eGFR for body surface area may not be appropriate for all populations and can introduce its own errors [24]. The prevailing and habitual dietary protein intake influenced by cultural and socioeconomic differences can also have profound effects on measured GFR as well as its estimation by serum creatinine-based formulas [28]. Concomitant malnutrition or chronic inflammation, so prevalent in many developing countries, will also likely have an effect on the parameters used in the KDOQI formulation to define 'chronic kidney disease'. Thus, the eGFR 'threshold' needed for defining 'true' CKD in the absence of any signs of 'kidney damage' is very likely to differ from population group to population group.

It is also obvious that estimation of the true burden of CKD in any particular region of the world cannot reliably be made by examining either a random sample of hospitalized patients, subjects who 'volunteer' for organized screening clinics or who are receiving regular ambulatory care under medical supervision [29]. These samples would be too biased to be considered representative of the population as a whole. For accurate estimation of the true community-based burden of CKD, a random and representative sample of the general population needs to be examined. The National Health and Nutrition Examination Surveys (NHANES) conducted periodically in the USA are about as representative of 'population-wide' surveys as can be practically executed [30]. These surveys, mostly based on single measurements of serum creatinine concentration and urinary albumin excretion, have indicated a prevalence of KDOQI-CKD stages $1-4$ of about $13.07 \%$ of adults ( $>20$ years of age) in the non-institutionalized population in the USA during the period of 19992004 (stage $1=1.78 \%$, stage $2=3.24 \%$, stage $3=7.69 \%$, stage $4=0.35 \%$ ) [30]. These percentages translate into 26.3 million individuals with stage $1-4$ CKD in the USA - about 55 times the number patients with treated ESRD in the USA as of December 31, 2005. Stage 3 CKD accounted for about $60 \%$ of the total number of subjects and $52 \%$ of these were over 60 years of age, predominantly females. Of those with stage 3 CKD, $76 \%$ had no abnormal proteinuria and 'dipstick' detectable proteinuria was detected in only $6 \%$. Of those defined as having stage 1 or 
Table 2. Estimation of population-wide prevalence of KDOQI-defined stage 1-4 CKD in selected countries ${ }^{\mathrm{a}}$

\begin{tabular}{|c|c|c|c|c|c|}
\hline \multirow[t]{2}{*}{ Country, study, year } & \multicolumn{5}{|c|}{ CKD prevalence, $\%$} \\
\hline & stage 1 & stage 2 & stage 3 & stage 4 & stage $1-4$ \\
\hline USA (NHANES, 1999-2004) & 1.8 & 3.2 & 7.5 & 0.35 & 13.1 \\
\hline China (Beijing, 2008) & 7.4 & 4.7 & 1.8 & $<0.10$ & 14.0 \\
\hline China (Inter-Asia, 2005) & na & na & 2.4 & 0.14 & - \\
\hline Norway (HUNT-II, 1999) & 2.7 & 3.2 & 4.2 & 0.16 & 10.3 \\
\hline Australia (AusDiab, 2003) & \multicolumn{2}{|c|}{5.1} & 10.9 & 0.30 & 16.3 \\
\hline Spain (EPIRCE, 2005) & \multicolumn{2}{|c|}{7.6} & \multicolumn{2}{|c|}{5.1} & 12.7 \\
\hline Spain (Hortega, 2004) & na & na & \multicolumn{2}{|c|}{8.0} & - \\
\hline Japan (7 prefectures, 2007) & na & na & 18.5 & 0.20 & - \\
\hline Thailand (InterAsia, 2005) & na & na & 13.4 & 0.60 & - \\
\hline United Kingdom (2005) & na & na & 5.5 & 0.31 & - \\
\hline Taiwan (2006) & na & na & \multicolumn{2}{|c|}{6.9} & - \\
\hline Iceland (2005) & na & na & \multicolumn{2}{|c|}{6.9} & - \\
\hline Mexico (2005) & na & na & & & - \\
\hline Averages ${ }^{\mathrm{b}}$ & \multicolumn{2}{|c|}{5.1} & 8.1 & 0.26 & 13.3 \\
\hline
\end{tabular}

\footnotetext{
a Countries selected on the basis of data from population-wide surveys, purported to be 'representative' of the population at large. eGFR classifications using the MDRD abbreviated formula unadjusted or adjusted for population characteristics [for details, see 21, 22, 29, 31-41].

b Averages exclude USA-NHANES; stage 1-2 includes all data; stage 3-4 includes only data where the two stages were separately evaluated.
}

2 CKD (with an eGFR $>60 \mathrm{ml} / \mathrm{min} / 1.73 \mathrm{~m}^{2}$ ), only $11 \%$ had 'macroalbuminuria' and $89 \%$ had 'microalbuminuria'. Thus, the great majority of subjects with KDOQIdefined stage 3 CKD will be older than 60 years of age, and have no abnormal proteinuria; whereas those with KDOQI-defined stage 1 and 2 CKD will most often be younger than 65 years of age and have predominantly microalbuminuria. Patients with KDOQI stage $4 \mathrm{CKD}$ (eGFR $15-29 \mathrm{ml} / \mathrm{min} / 1.73 \mathrm{~m}^{2}$ ) are far less prevalent than all of the other stages of CKD (accounting for $<3 \%$ of the total KDOQI CKD stages 1-4) [30]. Subjects with stage 4 CKD are also mostly over 60 years of age and $66 \%$ have abnormal proteinuria. Globally, approximately $12-16 \%$ of the population is over age 60 years, so the estimates of global CKD burden need to be adjusted for the age profile of the population under study. Use of the KDOQI formulation for estimating CKD prevalence in populations having a higher proportion of older individuals will pari passu lead to a higher prevalence of KDOQI-defined CKD; CKD prevalence, as defined by KDOQI, will track with the eGFR values for the population as a whole.

Is it appropriate to label older (otherwise healthy) individuals with eGFR values that are within the 95\% confidence intervals for age and gender as having CKD in the absence of other manifestation of 'kidney damage'? We think not. Labeling individuals with 'normal' eGFR $(>60$ $\mathrm{ml} / \mathrm{min} / 1.73 \mathrm{~m}^{2}$ ) and only isolated 'microalbuminuria' without diabetes, hypertension or obesity of having CKD may also be inappropriate. If these subjects were also excluded, the overall prevalence of 'CKD' would likely be less than $5 \%$ of the population. The extent of the 'false positive' error rates introduced by the lack of confirming values of eGFR in epidemiological studies is not known with precision, but they have been as high as $30 \%$ in some studies [31]. If all of these 'adjustments' were taken into account, the prevalence of CKD would decline to about 3.5 from $13.07 \%$ or to 7.04 from 26.3 million; a reduction in prevalence counts of CKD equivalent to about $19,300,000$ persons in the USA alone.

Studies of the prevalence of CKD carried out in population-wide surveys other than the USA have provided varied results [20-23, 32-42] (table 2). Most of these studies have applied the KDOQI-CKD classifications without any modifications, while a few have attempted to develop new eGFR estimating equations more appropriate for the population characteristics $[22,23]$. These studies have generated an estimated total population burden of KDOQI-defined stages 1-4 CKD of about 13.2\% (unweighted average of all studies; range 10.3-16.3\% (table 2)), which is surprisingly close to that estimated for 
Table 3. Stage 3-5 CKD prevalence in UK, $2005^{\mathrm{a}}$

\begin{tabular}{llll}
\hline & \multicolumn{3}{l}{ Prevalence of CKD $(\%)$ by eGFR $\left(\mathrm{ml} / \mathrm{min} / 1.73 \mathrm{~m}^{2}\right)$} \\
\cline { 2 - 4 } & $30-59$ & $15-29$ & $<15$ \\
\hline All genders & 18.0 & 0.7 & 0.19 \\
Females only & 22.0 & 0.8 & 0.15 \\
Males only & 12.6 & 0.5 & 0.18 \\
\hline
\end{tabular}

a Adapted from NEOERICA [for details, see 47].

Table 4. Ratio of stage 3-5 CKD prevalence (per million population) to treated ESRD (RRT) incidence (per million population) ${ }^{\mathrm{a}}$

\begin{tabular}{llc}
\hline Age group & Males & Females \\
\hline $45-64$ years & 220 & 310 \\
$55-64$ years & 276 & 873 \\
$65-74$ years & 364 & 1,114 \\
$75-84$ years & 510 & 1,737 \\
\hline
\end{tabular}

${ }^{\text {a }}$ Data abstracted from NEOERICA, 2005, and the UK ESRD Registry [for details, see 47].

the USA from NHANES [30]. Indigenous populations, hospitalized patients, nursing home residents or those who have had laboratory measurement of a serum creatinine level by the direction from their physician understandably have much higher estimates of prevalence of CKD [43-45].

It seems clear to us that a population-wide study of CKD prevalence which uses the $2002 \mathrm{KDOQI-CKD}$ formulation in an unmodified fashion and which also uses the standard, re-expressed four-variable MDRD formula for determining eGFR based on single measurements of serum creatinine concentration will greatly overestimate the 'true' prevalence of CKD. We doubt seriously that almost $820,000,000$ of the world's 6.2 billion persons have 'true' CKD. Adjustment of eGFR according to geographic ancestry (Black vs. non-Black) in the MDRD equation can also be very problematical in populations where geographic ancestry is very diverse, such as in South America.

Very few international comparisons of the prevalence of CKD and treated ESRD have been conducted. In one such comparison, Hallan et al. [34] found that the prevalence of KDOQI-defined CKD stages 3-4 was very similar in Norway (4.36\% in 1995-1997) compared to the USA $(5.01 \%$ in $1998-1994)$. The extraordinary observation that emerged was that the treated ESRD incidence in
Norway was 106 per million population per year (pmpy) compared to 308 pmpy in the USA and the ratio of stage 3-4 CKD prevalence (pmpy) to treated ESRD incidence (pmpy) ratio in Norway was 416 while it was 163 in the USA, a 2.55 -fold difference. These comparisons were made for the Caucasian population only since Blacks were not represented in the Norwegian sample. It was reasonably assumed that access to and indications for initiating RRT and the competing mortality from CVD during the course of CKD were equivalent in the two countries. The large difference in the risk of needing and receiving treatment for ESRD despite an equivalent prevalence of later stages of CKD remains unexplained. Differences in the rates of progression of CKD (higher in the USA) were offered as a potential cause [34]. An important implication from this study is that one cannot easily translate the burden of CKD in the community at large into an anticipated need for ESRD treatment. Indeed, among individuals having CKD stage 1-4, only a tiny percentage will require ESRD treatment in succeeding years $[31,46]$. Estimates for the CKD to treated ESRD 'transition' rate are about $0.15-0.2 \%$ per year of follow-up for stage $3 \mathrm{CKD}$, at least over 10-25 years. Higher 'transition' values are observed for stage $4 \mathrm{CKD}$. One of us (C.W.) conducted an analysis of the ratio of KDOQI-defined CKD prevalence to treated ESRD incidence in the UK using the NEOERICA estimates and the UK Renal Registry (tables 3, 4) [47]. This ratio rose from 220 to 510 for males in the 45- to 54-year age group compared to the 75- to 84-year age group. The difference was even more striking in females. The same ratio increased from 310 to 1,737 in the 45 - to 54-year age group compared to the 75to 84-year age group. Apparently, at least in the UK, elderly women (75+ years old) with KDOQI-defined CKD havelittle risk of developing treated ESRD (only $0.6 / 1,000$ ) (table 4). Such cross-sectional analyses need to be confirmed with longitudinal data in other populations.

The main driving force for rising rates of treated ESRD seen in developing countries, but now abating in more developed nations, is not likely to be the changing burden of stages 1-3 CKD prevailing in the community at large $[5,48]$. Rates of progression of established 'bona-fide' stage $4 \mathrm{CKD}$ and access to RRT for those with stage 5 CKD are far more important determinants of the overall incidence of treated ESRD. Obviously, these observations have critical importance for public health measures designed to diminish the prevalence of treated ESRD, since they help to define the 'target' population for control measures directed at reducing the burden of treated ESRD. 


\section{What Can Be Done to Improve the Assessment of the Global Burden of Chronic Kidney Disease?}

Very clearly, the global burden of CKD is not very well understood, particularly in developing nations, and much more epidemiological research is needed. This review has convinced us that the definitions of disease determine the estimates of the burden of disease, a not unexpected result. As applied to CKD, this predicts that a flawed definition (either too all-encompassing or too restrictive) will lead to inaccurate estimates of true prevalence of disease. The widespread use of the 2002 KDOQI system for diagnosis and staging of individuals with 'so-called' CKD has likely led to a significant overestimation of the global burden of true CKD. This problem has been compounded when the MDRD eGFR formula was not adapted to the characteristics of the population. The current KDOQI definitions for CKD stages 1-3 are very much in need of revision if we are to obtain a clearer picture of the true global burden of CKD.

This is not a trivial issue. Hundreds of millions of individuals around the globe may be labeled as having 'chronic kidney disease' when in fact they do not. False reassurance that $\mathrm{CKD}$ is not present in an individual is an equally daunting issue. Until we have a better understanding of the dynamics of the global burden of true instead of faux CKD and how individual population characteristics modify this burden, legitimate public health measures to identify and control CKD will be hampered.

As a first approximation of the needed changes, one should focus on stratifying the qualifying levels of eGFR for definition of CKD by age and gender. An absolute threshold of eGFR for defining CKD needs to be abandoned and substituted with a percentile distribution adjusted for age and gender, similar to height for age (and gender) charts used by pediatricians for many decades to track the growth of children. In our opinion, 'microalbuminuria' alone should not be regarded as a qualifying criteria for the diagnosis of CKD, but should be relegated to its proper status as a 'risk factor' for possible later development of CKD. Risk factors should not be considered as diseases for the purpose of classification. The current stages 1 and 2 KDOQI-CKD need to be collapsed into a single stage, due to inaccuracies in differentiating these stages based on eGFR measurements alone. Finally, geographicand ancestry-specific coefficients for the MDRD formula (or any other formula designed to estimate GFR) should be developed by appropriate comparisons of the results of the estimating formula with true GFR measurements in a group of individuals, of broad age limits, representative of both healthy and diseased (with evidence of chronic kidney damage) individuals in the population as a whole.

Armed with reliable knowledge regarding a priori prevalence of disease, one can then determine the potential effectiveness and cost of any prospectively designed disease control program. Expectations for the effectiveness of screening for CKD (number needed to screen to prevent a single case of ESRD or a single case of premature death due to CVD) can then be analyzed. Control programs directed at prevention of treated ESRD or CVD through early identification of CKD should be both realistic and based on better longitudinal studies of the global prevalence of progressive disease.

\section{References}

1 El Nahas M, Bello AK: Chronic kidney disease: the global challenge. Lancet 2005;365: 331-340.

$\checkmark 2$ KDOQI clinical practice guidelines for chronic kidney disease: evaluation, classification and stratification. Am J Kidney Dis 2002;39:S1-S266.

32007 Annual Report: Atlas of chronic kidney disease and end-stage renal disease in the United States. Am J Kidney Dis 2008;51 (suppl 1):S1-S319.

4 Levey AS, Eckardt KU, Tsukamoto Y, Levin A, Coresh J, Rossert J, De Zeeuw D, Hostetter TH, Lamiere N, Ecknowyan G: Definition and classification of chronic kidney disease: a position statement from kidney disease: improving global outcomes. Kidney Int 2005;67:2089-2100.
5 Glassock RJ, Winearls C: An epidemic of chronic kidney disease: fact or fiction? Nephrol Dial Transplant 2008;23:11171121.

6 Bauer C, Melamed ML, Hostetter TH: Staging of chronic kidney disease: time for a course correction. J Am Soc Nephrol 2008; 19:844-846.

7 Poggio ED, Rule AD: Can we do better than a single estimated GFR threshold when screening for chronic kidney disease? Kidney Int 2007;72:534-536.

8 Levey AS, Bosch JP, Lewis JB, Greene T, Rogers N, Roth D: A more accurate method to estimate glomerular filtration rate from serum creatinine: a new prediction equation. Ann Intern Med 1999;130:461-470.
-9 Levey AS, Coresh J, Greene T, Marsh J, Stevens LA, Kusek JW, Van Lente F, for the Chronic Kidney Disease Epidemiology Collaboration: Expressing the Modification of Diet in Renal Disease Study equation for estimating glomerular filtration rate with standardized serum creatinine values. Clin Chem 2007;53:766-772.

10 DuBois D, DuBois E: A formula to estimate the approximate surface area if height and weight are known. Arch Intern Med 1916;17: 863-871.

11 Stevens LA, Coresh J, Feldman HI, Greene T, Lash JP, Nelson RG, Rahman M, Deysher AE, Zhang Y, Schmid CH, Levey AS: Evaluation of the Modification of Diet in Renal Disease Study equation in a large diverse population. J Am Soc Nephrol 2007; 18:27492757. 
12 Mogenson CE: Microalbuminuria, blood pressure and diabetic renal disease: origin and ideas. Diabetologia 1999;42:263-285.

-13 Jones CA, Francis ME, Eberhardt MS, Chavers B, Coresh J, Engelgau M, Kusek JW, Byrd-Holt D, Narayan KM, Herman WH, James CP, Salive M, Agodoa LY: Microalbuminuria in the US population: third National Health and Nutrition Examination Survey. Am J Kidney Dis 2002;39:445-459.

14 Comper WD: JASDN Debates. Resolved: normal glomeruli filter nephrotic levels of albumin: pro. J Am Soc Nephrol 2008;19: 427-430.

15 Haraldsson B, Deen WM: JASN Debates. Resolved: normal glomeruli filter nephrotic levels of albumin: con. J Am Soc Nephrol 2008;19:430-432.

16 De Zeeuw D, Hillege HL, de Jong PE: The kidney, a cardiovascular risk marker and a new target for therapy. Kidney Int 2005(sup$\mathrm{pl}): S 25-\mathrm{S} 29$.

- 17 Brantsma AH, Bakker SJ, de Zeeuw D, de Jong PE, Gansevoort RT: Urinary albumin excretion as a predictor of the development of hypertension in the general population. J Am Soc Nephrol 2006;17:331-335.

- 18 Kestenbaum B, Rudser KD, de Boer IH, Peralta CA, Freid LF, Shlipak MG, Palmas W, Stehman-Breen C, Siscovick DS: Differences in kidney function and incident hypertension: the multi-ethnic study of atherosclerosis. Ann Intern Med 2008;148:501-508.

19 Couser WG: Chronic kidney disease - the promise and the perils. J Am Soc Nephrol 2007;18:2803-2805.

-20 Wetzels JF, Kiemeney LA, Swinkles DW, Willems HL, den Heijer M: Age- and genderspecific reference values of estimated GFR in Caucasians: the Nijmegen Biomedical Study. Kidney Int 2007;72:632-637.

21 Wetzels JP, Willems HL, den Heijer M: Ageand gender-specific reference values of estimated glomerular filtration rate in a Caucasian population: results of the Nijmegen Biomedical Study. Kidney Int 2008;73:657658.

22 Ma YC, Zuo L, Chen JH, Luo Q, Yu XQ, Li Y, Xu JS, Huang SM, Wang LN, Huang W, Wang $\mathrm{H}, \mathrm{Xu}$ GB, Wang HY: Modified glomerular filtration rate estimating equations for Chinese patients with chronic kidney disease. J Am Soc Nephrol 2006;17:29372944.

- 23 Inai E, Horio M, Iseki K, Yamagata K, Watanabe T, Hara S, Ura N, Kiyohara Y, Hirakata $\mathrm{H}$, Moriyama T, Ando Y, Nitta K, Inaguma D, Narita I, Ito H, Wakai K, Yasuda Y, Tsukamoto $\mathrm{Y}$, Ito S, Makino $\mathrm{H}$, Hishida A, Matsuo S: Prevalence of chronic kidney disease in the Japanese general population predicted by the MDRD equation modified by a Japanese coefficient. Clin Exp Nephrol 2007;11: 156-163.

24 Delanaye P, Radermecker RP, Rorive M, Depas G, Krzesinski JM: Indexing glomerular filtration rate for body surface area in obese patients is misleading: concept and example. Nephrol Dial Transplant 2005;20:20242028.
-25 Kallner A, Ayling PA, Khatami Z: Does eGFR improve the diagnostic capability of Screatinine concentration results? A retrospective population-based study. Int J Med Sci 2008;5:9-17.

26 Giles PD, Rylance PB, Crothers DC: New results from the Modification of Diet in Renal Disease Study: the importance of clinical outcomes in test strategies for early chronic kidney disease. QJM 2008;101:155-158.

27 Stevens LA, Coresh J, Schmid CH, Feldman HI, Froissart M, Kusek J, Rossert J, van Lente F, Bruce RD 3rd, Zhang YL, Greene T, Levey AS: Estimating GFR using cystatin C alone and in combination with serum creatinine: a pooled analysis of 3,418 individuals with CKD. Am J Kidney Dis 2008;51:395-406.

-28 Barai S, Ghambhir S, Prasad N, Sharma RK, Ora M, Kumar A, Gupta A, Parasar DS, Suneetha B: Levels of GFR and protein-induced hyperfiltration in kidney donors: a single-center experience in India. Am J Kidney Dis 2008;51:407-414.

29 Jaar BC, Khatib R, Plantinga L, Boulware LE, Powe N: Principles of screening for chronic kidney disease. Clin J Am Soc Nephrol 2008; 3:601-609.

30 Coresh J, Selvin E, Stevens LA, Manzi J, Kusek JE, Eggers P, van Lente F, Levey AS: Prevalence of chronic kidney disease in the United States. JAMA 2007;298:2028-2047.

- 31 Eriksen BO, Ingebretsen OC: The progression of chronic kidney disease: a 10-year population-based study of the effects of gender and age. Kidney Int 2006;69:375-382.

32 Zhang L, Zhang P, Wang F, Zuo L, Shi Y, L G, Jiao S, Liu Z, Liang W, Wang H: Prevalence and factors associated with CKD: a population study from Beijing. Am J Kidney Dis 2008; $51: 373-384$.

33 Chen J, Wildman RP, Gu D, Kusek JW, Spruill M, Reynolds K, Liu D, Hamm LL, Whelton PK, He J: Prevalence of decreased kidney function in Chinese adults aged 3574 years. Kidney Int 2005;68:2837-2845.

34 Hallan SI, Coresh J, Astor BC, Asberg A, Powe NR, Romundstad S, Hallan HA, Lydersen S, Holmen J: International comparison of the relationship of chronic kidney disease prevalence and ESRD risk. J Am Soc Nephrol 2006;17:2275-2284.

35 Chadban SJ, Briganti EM, Kerr PG, Dunstan DW, Welborn TA, Zimmet PZ, Atkins RC: Prevalence of kidney damage in Australian adults: the AusDiab study. J Am Soc Nephrol 2003;14(suppl 2):S31-S138.

36 Otero A, Gayoso P, Garcia F, de Francisco AL, EPRICE Study Group: Epidemiology of chronic renal disease in the Galician population: results of the pilot Spanish EPIRCE study. Kidney Int Suppl 2005;99:S16-S19.

37 Simal F, Martin Escudero JC, Bellido J, Arzua D, Mena FJ, Gonzales Melgosa I, Alvarezx Hurtado AA, Tabuyo MB, Molina A Prevalence of mild to moderate chronic kidney disease in the general population of Spain. Hortega Study Nefrologia 2004;24: 329-332.
38 Perkovic V, Cass A, Patel AA, Suriyawongpaisal P, Barzi F, Chadban S, McMahon S, Neal B; InterASIA Collaborative Group: High prevalence of chronic kidney disease in Thailand. Kidney Int 2008;73:473-479.

- 39 De Lusignan S, Chan T, Stevens P, O’Donoghue D, Hague N, Dzregah B, Van Vlymen J, Walker M, Hilton S: Identifying patients with chronic kidney disease from general practice computer records. Fam Pract 2005;22:234-241.

40 Hsu CC, Hwang SJ, Wen CP, Chang HY, Chen T, Shiu RS, Horng SS, Chang YK, Yang WC: High prevalence and low awareness of CKD in Taiwan: a study on the relationship between serum creatinine and awareness from a community representative survey. Am J Kidney Dis 2006;48:727-738.

41 Victorsdottir O, Palsson R, Andresdottir $\mathrm{MB}$, Aspelund T, Gudnason V, Indridason OS: Prevalence of chronic kidney disease based on estimated glomerular filtration rate and proteinuria in Icelandic adults. Nephrol Dial Transplant 2005;20:1799-1807.

42 Amato D, Alvarez-Aguilar C, CastanedaLimones R, Rodriquez E, Avila-Diaz M, Arreola F, Gomez A, Ballesteros H, Becerril R, Paniagua R: Prevalence of chronic kidney disease in an urban Mexican population. Kidney Int 2005(suppl):S11-S17.

43 McDonald SP, Maguire GP, Hoy WE: Renal function and cardiovascular risk factors in a remote Australian Aboriginal community. Nephrol Dial Transplant 2003;18:15551561.

44 Scavine M, Stidlye CA, Paine SS, Shah VO, Tentori F, Bobelu A, Welty TK, MacCluer JW, Zager PG: The burden of chronic kidney disease among the Zuni Indians: The Zuni Kidney Project. Clin J Am Soc Nephrol 2007; 2:509-516.

45 Gao S, Manns BJ, Culleton BF, Tonelli M, Quan H, Crowshoe L, Ghali WA, Svensson LW, Hemmelgarn BR: Alberta Kidney Disease Network. Prevalence of chronic kidney disease and survival among aboriginal people. J Am Soc Nephrol 2007;18:2953-2959.

46 Isahni A, Grandits GA, Grimm RH, Svendsen KH, Collins AJ, Prineas RJ, Neaton JD: Association of single measurements of dipstick proteinuria, estimated glomerular filtration rate and hematocrit with 25 -year incidence of end-stage renal disease in the multiple risk factor intervention trial. J Am Soc Nephrol 2006;17:1444-1452.

-47 Stevens PE, O’Donoghue DJ, de Lusignan S, Van Vlymen J, Kleber B, Middleton R, Hague N, New J, Farmer CK: Chronic kidney disease management in the United Kingdom: NEOERICA project results. Kidney Int 2007; 72:92-99.

- 48 Hsu CY, Go AS, McCulloch CE, Darbinian J, Iribarren C: Exploring trends in the likelihood of receiving treatment for end-stage renal disease. Clin J Am Soc Nephrol 2007;2: 81-88. 


\section{Editorial Comment}

M. El Nahas, Sheffield

The minireview by Glassock and Winearls, in the current issue of Nephron Clinical Practice, highlights major issues relating to the current classification of CKD. Whilst there is no doubt that the KDOQI/KDIGO classification of CKD has contributed considerably to increasing awareness of CKD and its scope, it has also been the subject of some controversy. This minireview raises concerns regarding a number of points relating to the classification and its implications. It questions the validity of a number of assumptions made by the CKD classification. It also expresses concern, shared by many, that the current 'epi- demic' of CKD reported since the introduction of the CKD classification may be a gross overestimate based on false assumptions such as the inclusion of those with microalbuminuria as suffering from CKD as well as those with age-related reduced kidney function, thus overinflating the number of CKD patients worldwide. Glassock and Winearls critically and wisely appraise the current situation and make timely recommendations. Time may have come for a revision of the current CKD classification. This minireview lays the foundation for such a debate. 